\title{
A PRÁTICA DO VANDALISMO NO PROCESSO DE ESCRITA COLABORATIVA DO VERBETE DA WIKIPÉDIA “SIMONE DE BEAUVOIR”*
}

\author{
Rafaela Bolsarin ${ }^{1}$ (D) \\ Petrilson Pinheiro ${ }^{1}$ (D)
}

\begin{abstract}
RESUMO: O objetivo deste artigo é discutir resultados de uma investigação sobre os modos como a prática do vandalismo pode impactar no processo de produção de um verbete da Wikipédia via práticas colaborativas de escrita. Para isso, tomamos como base as noçóes de Web 2.0 e práticas colaborativas de escrita para analisar ediçóes do verbete "Simone de Beauvoir" que, devido a uma questão do Exame Nacional do Ensino Médio (ENEM) que fez uso de uma frase da filósofa Simone de Beauvoir, passou a ser alvo constante de vandalismo. Como resultado deste trabalho, nota-se que o processo de produção do verbete "Simone de Beauvoir" constitui, na perspectiva dos novos letramentos, um conjunto amplo e difuso de pessoas, interesses, inteligências e técnicas que promovem o projeto coletivo de escrita da Wikipédia.
\end{abstract}

Palavras-chave: Vandalismo. Wikipédia. Web 2.0. Novo ethos. Práticas colaborativas de escrita.

\section{THE PRACTICE OF VANDALISM IN THE COLLABORATIVE WRITING PROCESS OF THE WIKIPEDIA ENTRY "SIMONE DE BEAUVOIR"}

ABSTRACT: This paper aims to discuss the results of a research on the ways in which the practice of vandalism can impact on the process of production of a Wikipedia entry through collaborative writing practices. To do so, we base upon the notions of Web 2.0 and collaborative writing practices to analyze the editions of the Wikipedia entry "Simone de Beauvoir", which, due to a question of the Brazilian National High School exam (ENEM) that made use of a statement from the philosopher, became a constant target of vandalism. As a result of this paper, one notes that the production process of the Wikipedia entry "Simone de

\footnotetext{
*Este trabalho está vinculado ao Grupo de Pesquisa do Conselho Nacional de Desenvolvimento Científico e Tecnológico (CNPq) Multiletramentos na Escola, coordenado pelo Professor Petrilson Pinheiro, da Universidade Estadual de Campinas, e parte da pesquisa de dissertação de mestrado intitulada "Negociação de sentidos na Wikipédia: um olhar por meio das práticas colaborativas de escrita", defendida por Rafaela Bolsarin, em 2017.

${ }^{1}$ Universidade Estadual de Campinas - Campinas (SP), Brasil. E-mail: rafa-bolsarin@uol.com.br; petrilson@iel.unicamp.br

DOI: 10.1590/ES0101-73302019189020
} 
Beauvoir" is constituted in the perspective of the new literacies, a broad and diffuse set of people, interests, intelligences and techniques that promotes the collective writing project of Wikipedia.

Keywords: Vandalism. Wikipedia. Web 2.0. New ethos. Collaborative writing practices.

\section{LA PRÁCTICA DEL VANDALISMO EN EL PROCESO DE ESCRITA COLABORATIVA DEL ARTÍCULO DE WIKIPEDIA "SIMONE DE BEAUVOIR"}

RESUMEN: El objetivo de este artículo es discutir resultados de una investigación sobre los modos como la práctica del vandalismo puede impactar en el proceso de producción de un artículo de Wikipedia vía prácticas colaborativas de escrita. Para eso, tomamos como base las nociones de Web 2.0 y prácticas colaborativas de escrita para analizar ediciones del artículo "Simone de Beauvoir" que, debido a una cuestión del Examen Nacional de la Enseñanza Media (ENEM) que hizo uso de una frase de la filósofa Simone de Beauvoir, pasó a ser albo constante de vandalismo. Como resultado de este trabajo, se nota que el proceso de producción del artículo "Simone de Beauvoir" constituye, en la perspectiva de las nuevas alfabetizaciones, un conjunto amplio y difuso de personas, intereses, inteligencias y técnicas que promueven el proyecto colectivo de escrita de Wikipedia.

Palabras clave: Vandalismo. Wikipedia. Web 2.0. Nuevo ethos. Prácticas colaborativas de escrita.

\section{Introdução}

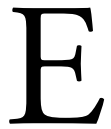

m uma sociedade cada vez mais conectada e mediada pelas tecnologias digitais da informação e comunicação (TIC), as possibilidades de práticas de letramento foram expandidas. Graças ao surgimento e à popularização da internet, emerge um novo modelo de comunicação, no qual o usuário pode participar de forma mais direta no ciberespaço, seja por meio de ferramentas de autoria, ou alcançando visibilidade pelas redes sociais, e até mesmo pela oferta de produtos e serviços que disputam espaço na rede (COPE \& KALANTZIS, 2013).

Com a Web 2.0 (O’REILLY, 2005), especialmente, o que se vê é um novo paradigma baseado em princípios e práticas centrados na participação colaborativa e voluntária dos usuários na internet (COPE \& KALANTZIS, 2011; PINHEIRO, 2013). Nesse cenário, diferentemente de enciclopédias tradicionais online, a Wikipédia se destaca por ser um objeto típico, considerado um dos exemplos de projetos dessa segunda fase da internet - afinal, os verbetes enciclopédicos wiki são todos criados e atualizados pelo trabalho voluntário de milhares de 
desconhecidos ao redor do mundo, que doam seu tempo e seu conhecimento para fazer ediçôes nos artigos.

Todavia, como era de se esperar em um ambiente aberto às contribuiçóes de qualquer pessoa, nem todas as edições visam à melhoria dos verbetes. Assim, como o próprio projeto convencionou chamar, a Wikipédia também está sujeita à ação de "vândalos", termo usado pela própria enciclopédia para designar usuários que fazem alteraçóes por má-fé, com o propósito de alterar deliberadamente verbetes por motivos pessoais ou para defender uma determinada visão político-ideológica.

Essa prática, bastante comum, eventualmente se torna manchete na imprensa, ganhando valor-notícia devido a algum acontecimento que motiva uma sequência de ediçóes de vandalismos. Foi o que aconteceu com o verbete da Wikipédia "Simone de Beauvoir", que virou alvo após uma frase da filósofa feminista ser utilizada em uma questáo da prova de Ciências Humanas e suas Tecnologias do Exame Nacional do Ensino Médio (ENEM) no ano de 2015².

$\mathrm{Na}$ época do acontecimento, o verbete "Simone de Beauvoir" ganhou destaque momentaneamente, passando a ser alvo constante de vandalismo, ao mesmo tempo em que acabou atraindo novas ediçóes: enquanto nos meses anteriores (desde sua criação, em outubro de 2004) o número de ediçóes ficava normalmente em menos de 10 por mês, entre outubro e novembro de 2015 houve 111 ediçóes no verbete.

Diante desses eventos e práticas, o que pretendemos neste artigo é discutir resultados de uma investigação sobre os modos como o vandalismo pode impactar na produção de um verbete, por meio da negociação (disputa) de sentidos via práticas colaborativas de escrita. Para tanto, tomamos como base as noçóes de Web 2.0 e novo ethos (LANKSHEAR; KNOBEL, 2007), aliados ao conceito de práticas colaborativas de escrita (PCE), para analisar ediçóes do verbete "Simone de Beauvoir", que compreendem o período de 24 de outubro de 2015 a 30 de novembro do mesmo ano.

\section{Web 2.0 e o novo ethos}

Ainda no final do século passado, Pierre Lévy (1999) já havia apontado que a internet se constituía como uma grande rede interconectada mundialmente; um processo de comunicaçáo "universal" sem "totalidade". Isso segue, segundo o autor, uma linha de comunicação que vem possibilitando aos navegantes da grande "rede" participar democraticamente de um modelo interativo feito para todos, consolidando, assim, a ideia de uma "aldeia global" que, indubitavelmente, se consolidou com o surgimento e o uso cada vez maior de novas TIC.

Nesse sentido, Castells (2003) assevera que a nova infraestrutura do mundo global tem como base as TIC, que introduziram uma mudança qualitativa 
em termos sociais, econômicos e tecnológicos ao tornar possível a realização de processos globais em tempo real. Contudo, ainda segundo o autor, o que caracteriza a era atual não é apenas a centralidade de conhecimentos e informação, mas a "aplicação desses conhecimentos e dessa informação para a geração de conhecimentos e de dispositivos de processamento/comunicação da informaçãa, em um ciclo de realimentação cumulativo entre a inovação e seu uso" (CASTELLS, 2003, p. 69). Por isso, a fragmentação e a individualização da economia global somente se tornaram possíveis, de acordo com o autor, devido à sua organizaçáo social em rede, tendo como base material as novas TIC, que geram, por sua vez, novos conhecimentos e dispositivos comunicativos para renovar a própria produção.

Esse fluxo contínuo de retroalimentaçáo de informação faz parte do que Pinheiro (2013, p. 95) chama de era da "(trans)informação", o momento sócio-histórico atual, em que a "informação não apenas circula em uma rede global (rede mundial de computadores), mas também sofre metamorfoses ao se tornar cada vez mais fluida e multifacetada, num processo de retroalimentação contínuo que transforma a si mesma”. Nessa era da (trans)informação, se constitui o que Castells (2003) denomina de "sociedade em rede", em que um conjunto de nós interconectados funciona como instrumentos adequados para a economia na era da globalização.

Essa sociedade em rede passou a ganhar uma maior inteligibilidade com uma diferenciação espacial que o próprio autor mais tarde veio a fazer entre "espaço dos lugares" e "espaço de fluxos". O primeiro caracteriza-se como um espaço de contiguidade produzido com base na comunicação entre as cidades em nível de interação social, troca de serviços, bens etc. em um "espaço cuja forma, função e significado estão contidos dentro de fronteiras de contiguidade física". O espaço de fluxos, por sua vez, constitui-se como espaços de "produção, transmissão e processamento do fluxo de informação à distância” (CASTELLS, 2010, p. 458, tradução nossa). Ainda segundo o autor, a relação resultante desses dois espaços é a de uma simultaneidade perene entre a localização e a globalização, em que prevalece o espaço dos fluxos, pois é nele que "a função e o poder das nossas sociedades estâo organizados, em que o domínio estrutural da sua lógica altera o significado e a dinâmica dos lugares" (CASTELLS, 2010, p. 458, tradução nossa).

Pode-se dizer que os espaços de fluxos passaram a ganhar um novo escopo com o advento da Web 2.0, que inaugura novas possibilidades comunicativas, tanto para o usuário quanto para os produtores de conteúdo. Isso porque, na Web 1.0, os usuários só tinham acesso à leitura dos conteúdos dos websites, ficando tanto a criação técnica do site quanto a produção de informação e entretenimento restritos aos profissionais da área. Já na Web 2.0, as ferramentas de autoria passaram a se tornar disponíveis a qualquer interessado, e o ciberespaço passou a ser amplamente ocupado por blogs, criados nas mais diversas plataformas, vlogs que chegam a milhôes de inscritos no YouTube, além de inúmeras postagens nas mais diversas redes sociais (LANKSHEAR; KNOBEL, 2007; PINHEIRO, 2013). 
Assim, como define Pinheiro, a lógica do "uso" foi ampliada para uma lógica de "participação", pois "dos sítios (sites) estáticos da rede, que apenas serviam informação, passou-se para o desenvolvimento de comunidades dinâmicas, inseridas numa interação entre o editor e a audiência" (PINHEIRO, 2014, p. 227). Nesse sentido, a relação entre produtor e usuário vem se tornando cada vez mais difícil de delimitar, criando a figura do produsuário (BRUNS, 2006), isto é, o usuário que também assume a função de produtor, explorando as possibilidades de autoria que a rede lhe oferece.

Nesse contexto, emergem e ganham espaço não só novas técnicas conjugadas a aparatos tecnológicos, cada vez mais avançados e presentes na vida social - , mas também um novo ethos, que se baseia, segundo Lankshear e Knobel (2007, p. 55, tradução nossa), na ideia de que "a mudança tecnológica se alinha com uma gama de valores cada vez mais populares". A esse respeito, os mesmos autores apontam:

O que é central para os novos letramentos não é o fato de que podemos agora 'procurar informaçóes on-line' ou escrever redaçóes usando um processador de textos ao invés de uma caneta ou uma máquina de escrever, mas sim que as novas tecnologias mobilizam tipos de valores, prioridades, sensibilidades, normas e procedimentos muito diferentes dos letramentos com os quais estamos familiarizados (LANKSHEAR \& KNOBEL, 2007, p. 7).

Para Lankshear e Knobel (2007), além de experimentarmos o surgimento de novos aparatos digitais (o que chamam de "new technical stuff), também precisamos passar por revisóes conceituais ("new ethos stuff"), para que possamos, de fato, pensar em novos letramentos. Ambos os termos (new technical stuffe new ethos stuff) subjazem à concepçáo de conteúdo gerado pelo usuário (user-generated content) da Web 2.0 (O’REILLY, 2005), a "fase da World Wide Web em que os usuários não estão mais limitados a uma visão passiva do conteúdo; eles podem continuamente interagir e colaborar uns com os outros em diálogos dinâmicos e em múltiplas camadas de mídias sociais" (PINHEIRO, 2014, p. 153-154).

Na perspectiva de Lankshear e Knobel (2007), é na relação entre novas técnicas e o novo ethos que se constituem "novos letramentos", que apresentam características como participação, inteligência coletiva, colaboração, compartilhamento e especialidade distribuída, em detrimento de valores como publicação editorial, inteligência e autoria individual, propriedade e especialidade centrada. Nessa perspectiva, podemos dizer que os novos letramentos vêm sendo a base das práticas das comunidades informais que se formam para construir a Wikipédia, que se constitui por meio de um ethos cuja base está no descentramento da noção de autoria, na participação em massa do processo produtivo e na participação e colaboração ativas por parte de seus usuários (PINHEIRO, 2014). Nas práticas de 
letramentos da Wikipédia, a produçáo dos verbetes depende da participação colaborativa da comunidade, cujos participantes cedem seu tempo e sua especialidade voluntariamente para construir uma inteligência coletiva. Isso integra a base para a construção de PCE no processo de produção dos verbetes da Wikipédia.

\section{Prática colaborativa de escrita na produção de verbetes enciclopédicos da Wikipédia}

O conceito de PCE que se adota neste trabalho se constitui com base na concepção de prática social proposta por Wenger (1998, p. 47), para quem:

O conceito de prática se refere a um fazer [...] mas a um fazer num contexto histórico e social que dá estrutura e significado ao que se faz. Neste sentido, prática é sempre prática social. [...] o conceito de prática salienta o caráter social e negociado tanto do explícito como do tácito das nossas vidas.

Nota-se que essa noção de prática não se restringe ao ato puro e simples de "fazer" alguma coisa; envolve algo mais amplo e dinâmico que, pela sua natureza social, intervém na definição de comunidades sociais de vários tipos. Em outras palavras, a prática social está inerentemente ligada à existência (ou à emergência) de comunidades ou conjuntos de pessoas que se reconhecem mutuamente como associadas a um conjunto de "fazeres". Nesse caso, o conceito de prática social assume uma perspectiva sócio-histórica, que envolve, portanto, um processo mais amplo, através do qual os sujeitos produzem e reproduzem as condiçôes (materiais e simbólicas) e relações sociais que possibilitam sua existência. Sob essa perspectiva, a prática social tem como ponto central exatamente a relaçáo entre o cotidiano e o não cotidiano, bem como a relação entre a experiência de cada um e as experiências do conjunto da sociedade, acumuladas ao longo de sua história.

É, pois, com base nessa concepção de "prática" que se entende neste trabalho a escrita colaborativa como resultado de um "processo iterativo e social que envolve uma equipe focada em um objetivo comum, que negocia, coordena e se comunica durante a criação de um documento comum" (LOWRY; CURTIS; LOWRY, 2004, p. 73, tradução nossa). A escrita colaborativa se constitui, desse modo, conforme apontam Allen et al. (1987), como um processo de produção compartilhada em que dois ou mais sujeitos, com habilidades complementares, interagem para criar um conhecimento compartilhado.

Em um trabalho colaborativo de escrita, portanto, ocorrem açóes conjuntas em que os sujeitos envolvidos se apoiam com o intuito de atingir objetivos comuns, por meio de relaçóes que se caracterizam por uma certa liderança compartilhada, confiança mútua e responsabilidade quanto às açôes a serem tomadas (DAMIANI, 2008). Assim, ao trabalharem em grupo, os "sujeitos podem 
produzir melhores resultados do que se atuassem individualmente", uma vez que pode ocorrer "complementaridade de capacidades, de conhecimentos, de esforços individuais, de opiniốes e pontos de vista, além de uma capacidade maior para gerar alternativas mais viáveis para a resolução de problemas" (PINHEIRO, 2013).

Neste trabalho, consideramos a produção de verbetes enciclopédicos na Wikipédia ${ }^{2}$ como uma escrita colaborativa, na medida em que a edição/atualização do verbete é o objetivo comum (seja ela para a sua melhoria, ou mesmo para vandalismo). Segundo Lowry, Curtis e Lowry (2004), a escrita colaborativa é construída e organizada com base nas seguintes partes: atividades de escrita, estratégias de escrita, modos de controle de documentos, papéis de escrita e modos de escrita.

As estratégias de escrita são as abordagens possíveis para a coordenação da produçáo do documento coletivo. Para os autores, há quatro tipos de abordagens: autor único (na qual uma única pessoa fica responsável pela redação do documento), em sequência (na qual a escrita ocorre sequencialmente, com uma pessoa por vez ficando responsável), em paralelo (na qual cada pessoa fica responsável por uma parte determinada e, embora todos escrevam ao mesmo tempo, o trabalho de cada um é separado) e reativa (na qual todos escrevem ao mesmo tempo, mas sem divisão de partes, ou seja, todos podem modificar todas as partes e, por essa razão, um acaba reagindo a partir da mudança que outros fazem).

Diretamente relacionados às estratégias, estão os modos de controle de documentos, que se constituem como abordagens de organização do acesso e da responsabilidade do documento. Segundo a taxonomia de Lowry, Curtis e Lowry (2004), esses modos de controle podem ser: centralizado (quando o documento é controlado por uma única pessoa durante sua produção), rotativo (quando há rotatividade no controle, mas somente uma pessoa controla por vez), independente (na qual vários controlam também, mas cada um só tem acesso à sua parte) e compartilhado (na qual todos os participantes compartilham o controle do todo e, consequentemente, a responsabilidade).

Os papéis, diretamente ligados às tarefas desempenhadas pelos participantes no grupo, variam muito, dependendo da natureza do documento a ser produzido, e podem ser definidos como "uma responsabilidade formal ou informal que o participante tem na escrita colaborativa" (LOWRY; CURTIS; LOWRY, 2004, p. 75, traduçáo nossa). Entre os mais comuns, podemos citar o escritor, como aquele que escreve o documento em uma parte ou no todo; o editor, que fica responsável pelo trabalho dos escritores e pode sugerir ou ele mesmo fazer alteraçôes no documento; e o líder, que tem a responsabilidade geral pelo grupo e por todo o processo de produção, não se limitando à escrita do documento.

Contudo, se por um lado a taxonomia serve para compreender práticas envolvendo escrita colaborativa, por outro, não esgota todas as possibilidades de uma atividade que é, por natureza, imprevisível. Assim sendo, cabe perceber uma 
distinção central que separa a Wikipédia — e outros projetos colaborativos — de produções mais restritas aos documentos: a relação de colaboração no processo como um todo.

Para Pinheiro (2013, p. 106), “a 'escrita colaborativa' não pressupõe, necessariamente, a colaboração ao longo de seu processo, mas, tão somente, no resultado final". Assim, para destacar práticas que valorizam a colaboração e a cooperação ao longo de todo o processo de produção, o autor conceitua o termo PCE para designar "práticas que sempre envolvem um processo de desenvolvimento da escrita; e que sempre envolvem, ainda que não seja durante todo o seu processo, a participação de duas ou mais pessoas" (PINHEIRO, 2013, p. 107).

Nesse sentido, podemos dizer que as práticas de produção de verbetes da Wikipédia se constituem como PCE. Contudo, por se configurar como um ethos de espaço aberto de produção colaborativa, as PCE da Wikipédia também obrigam a comunidade a lidar com as consequências dessa política de acesso e participação a qualquer interessado, que faz, portanto, interagir (não necessariamente de modo pacífico) diversos tipos de pessoas e de práticas. Uma das práticas mais comuns no processo colaborativo de produção de verbetes na Wikipédia é o vandalismo.

\section{A Wikipédia e o vandalismo}

A Wikipédia é uma enciclopédia on-line, produzida e distribuída sob os princípios da Web 2.0, e está disponível para qualquer interessado — tanto para leitura dos verbetes quanto para participaçáo nas suas ediçóes. Para quem se interessa pela última atividade, o processo é muito simples: basta acessar o verbete de seu interesse e escolher uma das opçóes para editar. Em seguida, o usuário já é redirecionado para a página de edição, onde poderá fazer a alteração que quiser no verbete. Terminada sua edição, o usuário deve clicar no botão "gravar alterações" e imediatamente o verbete será atualizado com a publicação da sua versão modificada.

Apesar de o projeto Wikipédia defender que qualquer pessoa possa contribuir a qualquer momento, ocasionalmente um verbete pode estar sob algum tipo de proteção, normalmente temporária. Conforme a descrição no projeto da Wikipédia:

Página protegida é uma página com um mecanismo de restriçóes controlado pelos administradores, que se refere à edição ou a movimentação da página. Proteger uma página é uma medida extrema, reservada normalmente aos casos nos quais a discussão não surte mais efeito ${ }^{3}$.

As medidas de proteção têm por objetivo "acalmar" uma guerra de ediçẫo — uma definição da Wikipédia para episódios em que editores revertem ${ }^{4}$ 
seguidamente edições uns dos outros em um verbete. Além da proteção da página (situação em que somente administradores podem editar), que costuma ser usada por um período breve ( 24 horas), existe também a semiproteção no nível de usuários confirmados (quando somente usuários autoconfirmados podem editar ${ }^{5}$ ). O período de semiproteção de um verbete varia muito, pois seu objetivo é conter o vandalismo e as guerras de edição, mas o projeto da Wikipédia defende que o ideal é que qualquer tipo de proteção seja sempre encerrado o mais rápido possível. No caso do verbete "Simone de Beauvoir", o período com semiproteçâo foi curto, porque se entendeu que os vandalismos foram ocasionados por um evento específico (a Prova do ENEM de 2015).

Além disso, os usuários podem ser cadastrados (quando optam por fazer um cadastro no site com login), não cadastrados (nesse caso, suas ediçóes são identificadas pelo número de seu IP), ou ainda possuir acesso a ferramentas do sistema (como o administrador, que pode proteger, desproteger e eliminar páginas, bloquear usuários, editar páginas protegidas etc.). Nos casos em que um verbete é submetido à semiproteção por usuário autoconfirmado, somente o usuário cadastrado tem permissão para editá-lo. Vale ainda destacar que, no que diz respeito à participação na comunidade da Wikipédia, apenas o usuário cadastrado tem direito a voto, ao acesso à página de usuário e a concorrer para ser administrador ${ }^{6}$.

O projeto colaborativo da Wikipédia já conta com mais de 30 milhōes de verbetes produzidos em diversos idiomas, sendo quase um milhão de artigos somente na versão lusófona, que reúne ainda 6.383 usuários ativos ${ }^{7}$. Considerando seu contexto de participação aberta a qualquer interessado, em uma organizaçáo mais heterárquica, característica da internet colaborativa, o vandalismo é uma prática comum e recorrente nesse espaço. Conforme conceito elaborado pela própria comunidade, vandalismo

é qualquer adição, remoção ou modificação de conteúdo feita de forma a comprometer deliberadamente a integridade da Wikipédia. Os tipos mais comuns de vandalismo são a inclusão de obscenidades ou humor chulo, branqueio de página ou inserção de texto sem sentido nos artigos ${ }^{8}$.

Nesse conceito, destaca-se o termo "deliberadamente", pois uma alteração só deve ser considerada vandalismo se houver má-fé por parte do autor. Os demais casos, ainda que considerados errôneos ou impróprios e, consequentemente, precisem ser removidos, não devem ser entendidos como vandalismos. No entanto, além da dificuldade de identificar se houve má-fé ou não, o vandalismo muitas vezes se torna difícil de ser detectado em situaçóes de troca de datas, informaçóes e estatísticas, por exemplo, que podem ter sido motivadas por algum tipo de atualização. O mesmo acontece com erros ortográficos: como saber quando foi uma distração, um erro legítimo ou uma tentativa de vandalismo? Por essa 
razão, convencionou-se na Wikipédia tratar esses supostos casos de "vandalismos" como "furtivos", com recomendação de aviso aos usuários envolvidos. Quando, porém, o usuário já foi avisado e continua fazendo alteraçóes deliberadamente, o ato é considerado vandalismo explícito e está sujeito à punição.

Tais distinçôes, quando olhamos para o verbete como produto, não são relevantes, uma vez que, independentemente da intenção do autor, o artigo é prejudicado e a alteração deve ser removida ou corrigida. Porém, quando consideramos a participação na Wikipédia como uma prática de letramento, a intenção ganha importância na medida em que a comunidade prevê que o vândalo deve ser advertido e, na reincidência, punido, podendo ser bloqueado temporariamente ou mesmo de maneira definitiva.

Para este artigo, escolhemos analisar o verbete "Simone de Beauvoir", cujo período de seleçáo de ediçôes para o recorte da análise reflete atos de vandalismo motivados pela questáo supracitada do ENEM, conforme apontamos na introdução. Por meio desse recorte, buscamos analisar o processo de produção do verbete, entendendo-o como PCE, na medida em que as ediçôes realizadas pelos participantes, associadas às interaçóes que ocorrem entre eles nos comentários das ediçóes, constituem-se como um processo de desenvolvimento de produçáo textual, envolvendo negociação e disputa de sentidos. Para tanto, tomamos como base o referencial teórico-analítico de escrita colaborativa proposto por Lowry, Curtis e Lowry (2004) que, conforme apontado na seção anterior, se baseia nas seguintes partes: atividades de escrita, estratégias de escrita, modos de controle de documentos, papéis de escrita e modos de escrita.

\section{Prática colaborativa de escrita no processo de construção do verbete "Simone de Beauvoir"}

Para analisar o verbete da Wikipédia "Simone de Beauvoir", foram inicialmente gerados dados relativos ao período de 24 de outubro de 2015 (primeiro dia de prova do ENEM e, portanto, início das repercussóes no verbete) a 30 de novembro do mesmo ano (data considerada como estabilizaçáo do verbete, uma vez que, no mês seguinte, as edições fazem uma pausa significativa, sendo registrada uma única edição em dezembro de 2015). Nesse período, houve um total de 111 ediçōes do verbete "Simone de Beauvoir". Para esta análise, porém, selecionamos alguns exemplos de ediçóes que busquem dar conta do uso do vandalismo na negociação e disputa de sentidos na produção do verbete.

A primeira interferência relacionada à questão do ENEM no verbete começou às $22 \mathrm{~h} 12$ no próprio dia 24 de outubro, isto é, poucas horas após a aplicação do exame do ENEM. Conforme é possível notar na Figura 1, a primeira edição sobre o ocorrido se deu de forma "objetiva", condizente com o projeto Wikipédia, na qual um determinado usuário sem cadastro acrescentou o trecho 
“Em 2015, no Exame Nacional do Ensino Médio (ENEM), uma das questóes envolvia a feminista". Tal edição, no entanto, permaneceu somente por 9 minutos, tendo sido revertida em seguida por um editor cadastrado. A alteração seguinte, ocorrida somente no dia posterior, ao adicionar o texto "Só não entendia nada de biologia", parece fazer referência à célebre frase, presente na questáo (ver nota 1), "Ninguém nasce mulher: torna-se mulher". Tal edição se configura, assim, como o primeiro vandalismo motivado pela questáo do ENEM, que foi revertido cerca de uma hora depois.

A reversão, como a realizada no exemplo acima, é uma reação comum aos vandalismos no verbete. Assim, embora a estratégia de escrita colaborativa global seja a escrita em sequência (LOWRY; CURTIS; LOWRY, 2004), uma vez que a ideia de elaboração do verbete é a de que cada usuário-participante da Wikipédia escreva um determinado texto e cada um dos demais membros complemente a tarefa, inserindo também suas contribuiçóes no texto inicial até chegar ao documento desejado, a prática de reverter ou desfazer uma edição é muito comum, e a entendemos também como uma reação possível ao vandalismo.

Tal prática se constitui através do modo de controle do documento (do verbete) do tipo compartilhado (LOWRY; CURTIS; LOWRY, 2004),

\section{Figura 1}

Imagem com printscreen das primeiras edições envolvendo a questão do ENEM; no destaque em amarelo estâo os trechos específicos das alteraçôes.

Simone Lucie-Ernestine-Marie Bertrand de Beauvoir, mais conhecida como Simone de Beauvoir (Paris, 9 de janeiro de 1908 - Paris, 14 de abril de 1986), foi uma escritora, filósofa existencialista e feminista francesa.

Escreveu romances, monografias sobre filosofia, politica, sociedade, ensaios, biografias e uma autobiografia.

Em 2015, no Exame Nacional do Ensino Médio (ENEM), uma das questões envolvia a feminista.

Simone Lucie-Ernestine-Marie Bertrand de Beauvoir, mais conhecida como Simone de Beauvoir (Paris, 9 de janeiro de 1908 - Paris, 14 de abril de 1986), foi uma escritora, filósofa existencialista e feminista francesa.

Escreveu romances, monografias sobre filosofia, politica, sociedade, ensaios, biografias e uma autobiografia.

Simone Lucie-Ernestine-Marie Bertrand de Beauvoir, mais conhecida como Simone de Beauvoir (Paris, 9 de janeiro de 1908 - Paris, 14 de abril de 1986), foi uma escritora, filósofa existencialista e feminista francesa.

Escreveu romances, monografias sobre filosofia, politica, sociedade, ensaios, biografias e uma autobiografia. Só não entendia nada de biologia. 
no qual todos os usuários-participantes compartilham o controle do verbete como um todo, tendo os mesmos acessos e privilégios de escrita ao longo de toda a atividade de produção textual, assumindo também as mesmas responsabilidades por sua elaboraçáo. Esse modo de controle de documento torna complexo o processo colaborativo de escrita na Wikipédia, pois, se por um lado, esse tipo de escrita possibilita uma maior distribuição de participação de usuários na elaboraçáo dos verbetes, por outro, a quase sincronicidade das alteraçóes textuais faz com que essa prática se torne, de uma certa forma, uma estratégia de escrita reativa, em que os usuários "reagem e se ajustam às mudanças e contribuiçóes de cada um do grupo, sem que haja necessariamente um planejamento prévio e uma coordenação explícita do texto a ser elaborado" (PINHEIRO, 2013, p. 117). Isso, não raro, provoca falta de controle (consenso) do documento, fruto de sobreposição, contradição, discordância ou disputa de ideias, como é o caso do vandalismo.

Nota-se que a consequência da prática de reversão para o processo colaborativo de escrita é o apagamento da inserçáo no verbete da parte considerada como vandalismo ("Só não entendia nada de biologia"). No entanto, mesmo desfazendo a ação de um vândalo, continuando o processo da escrita colaborativa a partir da versão anterior, e não da versão modificada, pode-se dizer que a prática do vandalismo contribui com a PCE e o aprimoramento do verbete, porquanto o editor se permite reagir - toma a iniciativa de alterar o verbete a partir dessa prática.

A insistência dos vandalismos pode também incentivar outros usuários sem cadastro a incorporar trechos e ideias provenientes dos vandalismos no texto. Isso parece ter sido o caso de uma ediçáo do verbete, realizada às $13 \mathrm{~h} 36$ no dia 25 de outubro, quando um usuário cria o tópico "2.1 Polêmica sobre pedofilia" (ver Figura 2). Embora, à primeira vista, não se possa dizer que esse tipo de inserção se configure explicitamente como um exemplo típico de vandalismo, com base no conceito de vandalismo da própria Wikipédia (ver seção anterior), o que fica claro é que tal edição não segue o padrão de verbete da enciclopédia, que, ao invés de criar um tópico com acesso (link) para artigos, notícias e outros locais que confirmem os dados do verbete, o faz para destacar um fato polêmico que implicitamente sugere a opinião pessoal de quem o elaborou em relação à filósofa Simone de Beauvoir.

Esse tópico ("Polêmica sobre pedofilia") é retomado no mesmo dia (15h51), após algumas disputas, quando outro usuário sem cadastro deixa um comentário no código-fonte, sinalizando que "Faltam fontes para sustentar esse texto", referindo-se ao tópico (Figura 3). Tal sinalização sobre a ausência de fontes parece ter voltado a atenção da comunidade para o tópico novamente, ocasionando sua retirada, que foi justificada com o seguinte comentário: "cópia não autorizada". Como se vê, a escrita em sequência, junto com o modo 
de controle de documentos compartilhado, assume papel central no processo de produção do verbete, pois foi somente após um usuário ter sinalizado atenção para o trecho que outro usuário, reagindo na sequência a essa edição, optou por retirá-lo.

Outro exemplo que mobilizou a produção do verbete de Beauvoir se deu quando um usuário cadastrado cria o tópico "Pedofilia" no verbete (Figura 4). Diferentemente do caso anterior ("Polêmica sobre pedofilia"), o usuário parece se enquadrar nos padrōes do projeto de produção de verbete, pois o faz por meio de um texto com dados e fontes, justificando que estava inserindo "informaçóes básicas sobre sua posição acerca da pedofilia”.

O tópico foi revertido ainda no mesmo dia da sua inserção no verbete. No entanto, ele náo foi simplesmente apagado. O assunto "pedofilia" passou a ser incorporado no verbete em uma versão seguinte (Figura 5), gerada a partir de uma grande revisão feita por Lucas ${ }^{10}$, um usuário cadastrado muito experiente (líder de edições e de inserção de texto no verbete em questão). O resultado disso foi que, sem usar o termo pedofilia, essa revisão adicionou o tema no tópico "Vida pessoal" (Figura 5), que posteriormente foi transformado em "Outros relacionamentos" (Figura 6), ao tratar de polêmicas na relação de Beauvoir com suas alunas, apresentando dados que foram referenciados com fontes e aprimorados na revisão, de modo a apenas manter no verbete informaçôes confirmadas por links. Nota-se, assim, que essa prática de vandalismo contribuiu para uma melhoria do verbete, justamente por ter fomentado sua revisão.

\section{Figura 2}

Imagem do índice após a inserção do tema no tópico específico "Polêmica sobre pedofilia".

Índice [esconder]

1 Primeiros anos

1.1 Familia

1.2 Educação

1.3 Sartre

2 Obra

2.1 Polêmica sobre pedofilia

3 Livros

4 Referências

5 Bibliografia

6 Ligações externas 


\title{
Figura 3
}

Comparação de duas edições: sinalização do assunto e sua consequente retirada.

\author{
Revisão das 15h51min de 25 de outubro de 2015 (editar) \\ (discussão) \\ $(\rightarrow$ Polêmica sobre pedofilia) \\ (Etiqueta: Editor Visual) \\ $\leftarrow$ Ver a alteração anterior
}

\section{Linha 53:}

Entre seus ensaios criticos cabe destacar "[[Le Deuxième Sexe|O segundo sexo]]" ([[1949]]), uma profunda análise sobre o papel das [[mulher]]es na sociedade; "A velhice" ([[1970]]), sobre o processo de envelhecimento, onde teceu criticas apaixonadas sobre a atitude da sociedade para com os anciãos; e "A cerimônia do adeus" ([[1981]]), onde evocou a figura de seu companheiro de tantos anos, Sartre.

$-$

$-$

=== Polêmica sobre pedofilia<!- Faltam fontes para sustentar esse texto. $.-\mathbf{>}=\mathbf{= =}$

Entre 1943 e 1944, quando a França estava sob ocupação nazista, Simone de Beauvoir trabalhou como diretora de sonografia para a Rádio Vichy. Radio Vichy era a estaçăo de rádio estatal na assim chamada"zone libre" (zona livre) da França, após a capitulação da República Francesa diante da Alemanha nazista em 1940. Dizemos "assim chamada" porque o regime de Vichy, embora teoricamente neutro do ponto de vista militar, era de fato um colaborador ativo do regime nazista e hoje é fato reconhecido por todos os lados envolvidos que a Rádio Vichy era porta-voz de fato da propaganda nazista nas ondas de rádio francesas.

Defensores de Beauvoir podem dizer que ela foi obrigada pelas circunstâncias a trabalhar lá, assim como muitos individuos agora alegam ter sido forçados a colaborar com a "Securitate" durante o regime comunista. Mas os manuscritos de Beauvoir durante o periodo, revelados posteriormente, contam uma história diferente.

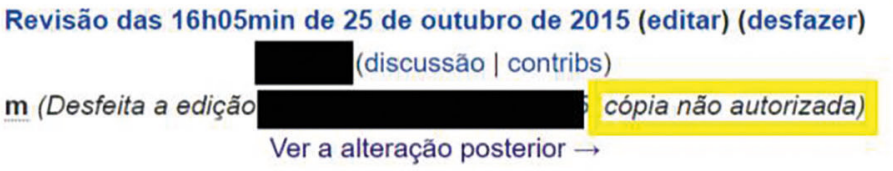

\section{Linha 53:}

Entre seus ensaios criticos cabe destacar "[[Le Deuxième Sexe|O segundo sexo]]" ([[1949]]), uma profunda análise sobre o papel das [[mulher]]es na sociedade; "A velhice" ([[1970]]), sobre o processo de envelhecimento, onde teceu criticas apaixonadas sobre a atitude da sociedade para com os anciãos; e "A cerimōnia do adeus" ([[1981]]), onde evocou a figura de seu companheiro de tantos anos, Sartre. 


\section{Figura 4}

\section{Tópico "Pedofilia" criado por um usuário cadastrado.}

\section{Pedofilia}

Beauvoir foi uma defensora da liberaçăo da pedofilia, tendo inclusive participado do manifesto de criaçăo do FLIP (Front de libération des pédophiles), fazendo uma discussăo muito clara sobre o assunto na Radio France Culture em Abril de 1978. [27][28]

\section{Figura 5 \\ Imagem do tópico criado por Lucas; números e palavras em azul indicam links para outras páginas.}

\section{Vida pessoal}

Apesar de de Beauvoir ter tido um relacionamento de longa data com Sartre, ela era conhecida por ter várias amantes do sexo feminino. A natureza de alguns desses relacionamentos, alguns dos quais ela começou enquanto trabalhava como professora, depois levou a uma controvérsia biográfica. ${ }^{[32][33] \mid 34][35]}$ Uma ex-aluna, Bianca Lamblin (originalmente Bianca Bienenfeld), em seu livro Mémoires d'une jeune fille dérangée, escreveu que quando era estudante tinha sido explorada por sua professora de Beauvoir, que estava em seus trinta anos na época. [36]

Em 1943, de Beauvoir foi suspensa do seu trabalho de ensino, devido a uma acusação de que ela tinha, em 1939, seduzido a aluna de Natalie Sorokine. ${ }^{[37]}$ Os pais de Sorokine previstas acusações formais contra de Beauvoir e como resultado, ela teve seu licença para lecionar na França revogada permanentemente. ${ }^{[38]}$ Ela e Sartre desenvolveram um padrão (que eles chamavam de "trio"), em que de Beauvoir iria seduzir suas alunas e, em seguida, transferi-as para Sartre. ${ }^{[39]}$ Ambos mais tarde se arrependeram depois de atribuir a sua responsabilidade a danos psicológicos identificados em, pelo menos, uma dessas meninas. ${ }^{[40]}$

Ela foi professora de filosofia até 1943 em escolas de diferentes localidades francesas, como Ruão e Marselha. Morreu de pneumonia em Paris, aos 78 anos. Encontra-se sepultada no mesmo túmulo de Jean-Paul Sartre no Cemitério de Montparnasse em Paris. ${ }^{[41]}$

\section{Figura 6}

Imagem comparativa: usuário sem cadastro apaga o trecho "Outros relacionamentos".

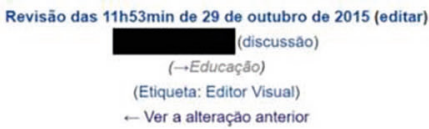

Linha 72

De Beauvoir escolheu nunca mais se casar e nẫ constitulu uma familia com Sartre, kref name=schneir / sendo que nunca teve filhos. <ref name=Schneir? Ifcite bookjauthor=Schneir, Mirlam|tule=Feminism in Our Time|year=1994|pubisher=Vintage Books page $=5$ |isbn=0.679.74508-4]|</rets Isto the deu tempo para conquistar um grau académico avancado, para lutar por causas politicas, para viajar, escrever, ensinar e ter amantes (masculinos e femininos - estes utimos multas vezes compartihados). <ret

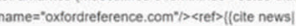

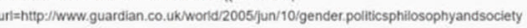
|location=Londres |work=The Guardian | first=Lisa | last=Appignanesi | tide=Our relationship was the greatest achievement of my life [ date=10 de junho de 2005]

$-$

$-$

Apesar de de Beauvoir ter tido um relacionamento de longa data com Sartse, ela era connecida por ter varias amantes do sexo ferninino. A natureza de alguns desses relacionamentos, alguns dos quais ela começou enquanto trabalhava como professora, depois levou a uma controversia blografica. <rets"A dangerous liaison: Simone de Beauvoir and Jean-Paul Sartre", By Carole Seymour-Jones (Londres 2008), page 216 and $274</$ reß $<$ ret> Thttp://www.independent.co.uk/arts.

- entertainment/books/reviews/sex-and-phllosophy-rethinking-de-beauvoir-and-sartre-byedward-fullbrook-and-kate-fullbrookbr-a-dangerous-liaison-by-carole-seymourjones$832532 \mathrm{htm} / \mathrm{New}$ studies aqree that Beauvoir is eclipsing Sartre as a philosopher and

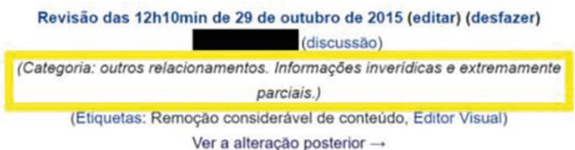

Linha 72:

De Beauvoir escolheu nunca mais se casar e nấo constituiu uma familia corn Sarte, cret name=Schneir $>>$ sendo que nunca teve fihos. <ret name=Schneir $>$ (lcite book|author=Schneir, Miriam|ute=Feminism in Our Time|year=1994|publisherzVintage Books |page=5|isbn=0.679.74508-4)] <irets isto the deu tempo para conquistar um grau académico avançado, para lutar por causas politicas, para viajar, escrever, ensinar e ter amantes (masculinos e femininos - estes uitimos multas vezes compartihados).<ref name $="$ oxfordreference.com" $/><$ ref $>$ [(cite news

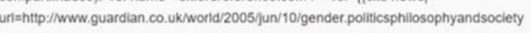
|location=Londres |work=The Guardian | first=Lisa | last=Appignanesi | tite= =ur relationship was the greatest achlevement of my life | date=10 de junho de 2005|| srets 
Contudo, por ter considerado, pouco tempo depois, que o verbete foi alvo de vandalismo, um editor adota a postura do silenciamento, apagando todo o trecho inserido e comentando "Informaçóes inverídicas e extremamente parciais" (Figura 6). Na sequência, então, a edição é revertida e o editor entra em disputa com outros usuários, o que culmina com a reinserção do trecho e a mudança do nível de proteção da página para autoconfirmados.

Devemos ressaltar aqui que, se por um lado, a postura de silenciamento se constitui como uma ferramenta para coibir o vandalismo, por outro, pode ser utilizada simplesmente para marcar relaçóes de poder, com o intuito de ignorar o trabalho alheio, em vez de utilizá-lo para criar algo melhor, conforme recomenda a própria comunidade da Wikipédia ${ }^{11}$. Tanto em um caso como em outro, ser ou não usuário cadastrado pode fazer uma diferença considerável, pois, em uma situação em que um verbete é submetido à semiproteção por usuário autoconfirmado, como no caso descrito, somente o usuário cadastrado tem permissão para editá-lo.

A disputa pelo tema continua com uma adição de conteúdo com fontes referenciadas, dessa vez em outro trecho, expandindo o assunto por outros locais do verbete. Novamente, o texto é aprimorado, ganhando um tópico exclusivo intitulado "Idade de consentimento". Cabe destacar que tal medida foi tomada por Lucas, usuário que já tinha se dedicado ao tema, o que sugere que foi a contribuição dos outros editores que possibilitou que ele então optasse por separar o tópico de maneira mais específica. O verbete, então, passa a ser marcado pela adição da tag de revisão (Figura 7), que foi inserida juntamente com o comentário "peço que os administradores avaliem a adequação desta tag, tendo em vista as controvérsias recentes".

Embora a tag seja rejeitada e excluída apenas 5 minutos depois pelo usuário Lucas, este assume o papel de líder na atividade de revisão final do verbete, fazendo uma série de ajustes e revisões, inclusive técnicas, deixando comentários como "expansão final e fim dos trabalhos de reformulação", "revisão final e outros ajustes" e "ampliação da introdução". Apesar da liderança assumida por Lucas na revisão, outros editores também participam, sendo um deles responsável pelos ajustes de trechos traduzidos, entre eles a substituição da palavra "explorada" por "abusada", que permanece até hoje para se referir à acusação de uma aluna contra Beauvoir.

Vale ainda destacar dois pontos no processo colaborativo de escrita do verbete: o primeiro deles é o fato de que, conforme apontamos anteriormente, o

\section{Figura 7}

Imagem da tag de revisão colocada pelo usuário.

Esta página fol marcada para revisăo, devido a inconsisténcias e/ou dados de confiabilidade duvidosa. Se tem algum conhecimento sobre tema, por favor, verifique e melhore a consistência e o rigor deste artigo. 
modo de controle de documentos compartilhado foi um dos fatores determinantes para a construção de PCE na elaboração do verbete. Afinal, se o controle ficasse limitado a um ou a poucos membros, os vandalismos seriam drasticamente reduzidos, uma vez que dificilmente um usuário que decida participar como vândalo cumpriria os requisitos para se tornar um dos responsáveis pelo verbete.

Esse ponto, por sua vez, se relaciona ao segundo: os papéis dos usuários-participantes. Isso porque, muito embora o documento e a responsabilidade sejam divididos igualmente entre todos, na prática, o projeto de produção do verbete só funciona porque alguns assumem uma maior responsabilidade para si, a ponto de vigiá-lo (cadastrando-se para receber notificações quando o verbete for editado), enquanto outros utilizam o acesso que lhes foi dado para praticar vandalismos.

Nesse sentido, apesar de a política de participação da Wikipédia apregoar uma participaçáo heterárquica entre os usuários, na prática, se um usuário é um participante ativo e cadastrado, ele se torna gradativamente conhecido e, consequentemente, adquire um respeito maior na comunidade. A exemplo disso podemos mencionar a participação de Lucas, que assumiu o papel de líder nas revisões, não apenas porque fez uma grande parte do trabalho de edição do verbete $^{12}$, mas, sobretudo, porque os demais usuários, ao realizarem suas ediçóes, o fazem a partir do que Lucas fez. É possível também dizer que a comunidade respeita e reconhece a liderança de Lucas por ele ser conhecido, cadastrado e administrador. Ele já atua na Wikipédia há nove anos, já criou mais de mil artigos e fez mais de cem mil ediçóes.

Por fim, após a atividade que identificamos como revisão final, notamos que, embora os vandalismos continuem, perdem o caráter político para dar lugar a ediçóes com ofensas e palavrôes, além de trollagens, termo usado para designar o comportamento de trolls, que são usuários que participam de uma comunidade ou de discussóes com o objetivo de provocar outros membros para atrapalhar o andamento da atividade.

Tal sequência gera outra proteção para autoconfirmados e, por fim, outra revisão geral, sem envolver polêmicas. O período analisado se encerra com a indicação de que o artigo foi eleito pela comunidade como "bom". Vale destacar que a votaçáo foi iniciada em 31 de outubro de 2015, ou seja, somente após o início dos vandalismos motivados pela prova do ENEM 2015.

Essa iniciativa sugere que, mais uma vez, os vandalismos acabaram incentivando, de alguma forma, o aprimoramento no verbete, chamando atenção da comunidade para sua elaboração (que se une para combater o vandalismo e preservar a qualidade do verbete) e incentivando sua revisáo, ao disputar sentidos naquele espaço (que, no caso, foi essencialmente a disputa pela acusaçáo de pedofilia). Isso pode ser percebido por meio das alteraçóes realizadas, representadas pela visão geral de duas versões do verbete "Simo- 
ne de Beauvoir" (Figura 8), em que a primeira versão do período analisado (de cima), ocorreu às $22 \mathrm{~h} 12$ do dia 24 de outubro de 2015 e a última versão (de baixo), às $17 \mathrm{~h} 43$ do dia 30 de novembro de 2015 .

Nota-se, portanto, que, na Wikipédia, um complexo espaço de fluxos (CASTELLS, 2010) típico da Web 2.0 (O’REILLY, 2005), a prática do vandalismo, ao gerar disputas que, de alguma forma, fomentam o aperfeiçoamento do verbete, constitui-se, de fato, como parte de um processo de produção compartilhada de escrita colaborativa, em que vários participantes, com habilidades complementares, interagem para criar um conhecimento compartilhado que vai além das habilidades individuais de cada um (ALLEN et al., 1987; PINHEIRO, 2013), buscando, assim, alternativas mais viáveis para a própria resolução do problema dos vandalismos presentes no verbete.

\section{Figura 8}

Imagem com as versóes do início e do final do período analisado.

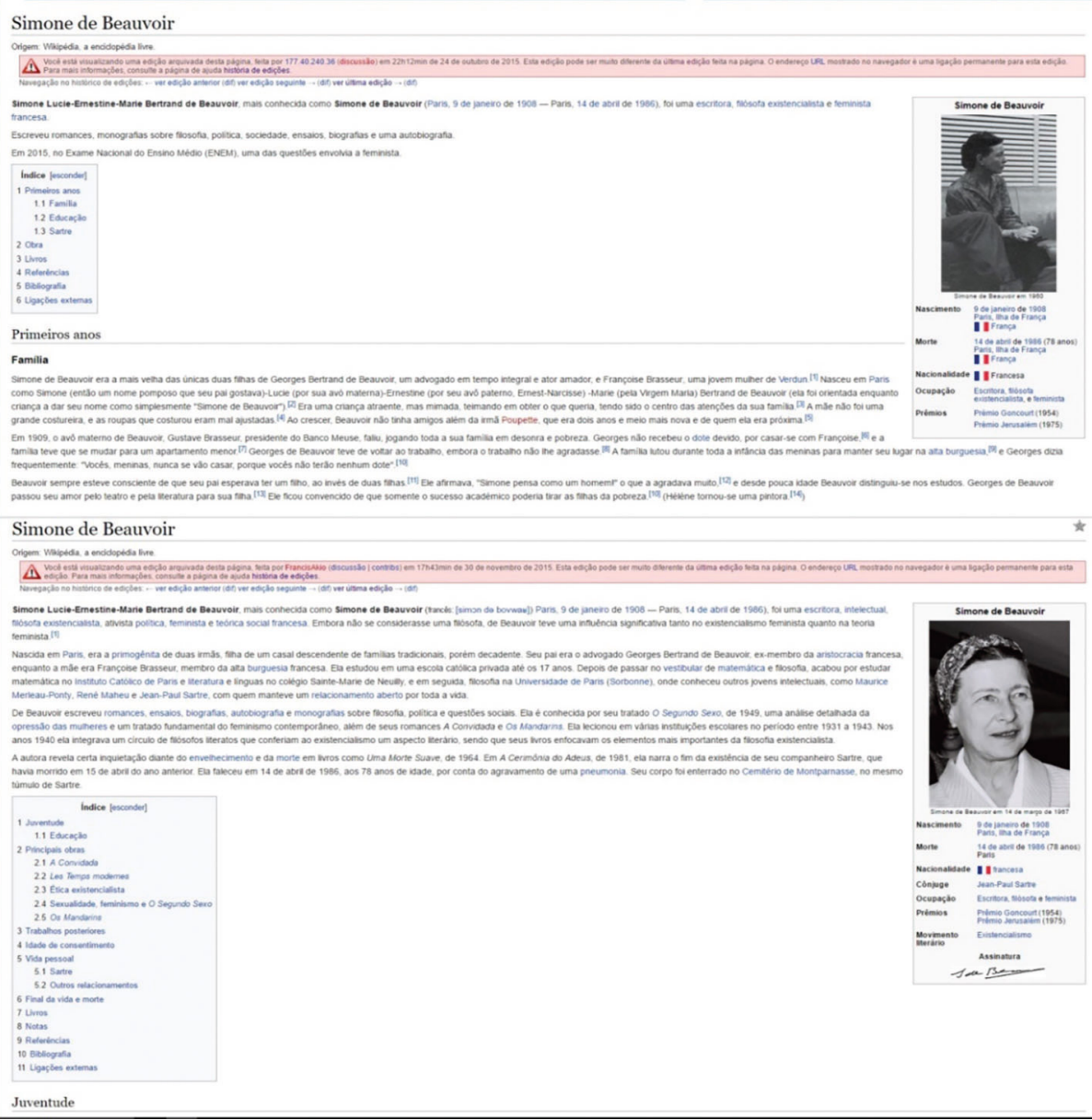




\section{Considerações finais}

Tomando como base as noções de Web 2.0 e novo ethos, relacionando-as ao conceito de PCE, buscamos neste artigo discutir uma questão específica no contexto de produção de verbetes da Wikipédia: como o vandalismo pode impactar na produção de um verbete, por meio da negociaçáo (disputa) de sentidos via PCE. Para, então, realizar tal investigaçáo, analisamos o processo de produção do verbete "Simone de Beauvoir", cujas ediçōes, ocorridas no período de 24 de outubro a 30 de novembro de 2015, foram fortemente influenciadas por uma questão do ENEM de 2015 que fez uso de uma frase da filósofa feminista Simone de Beauvoir, dando, assim, bastante visibilidade ao verbete, que passou, entâo, a ser alvo constante de vandalismo.

Contudo, se, por um lado, o verbete esteve nesse período exposto a vandalismos, por outro, ao fazer parte da Wikipédia, um espaço de fluxos complexo (CASTELLS, 2010), possibilitou que membros da própria comunidade elaborassem diversas versóes para o verbete, o que contribuiu para aprimorá-lo. Nesse sentido, pudemos notar que as disputas de sentidos em relaçáo a questóes controversas, como a "polêmica sobre pedofilia", mesmo parecendo terem sido inicialmente motivadas por uma prática de vandalismo, foram incorporadas por meio de um processo colaborativo das ediçóes do verbete.

Com efeito, ao lidar com PCE, sobretudo em um contexto de produção em que a participação dos usuários é grande e o controle do texto a ser produzido não é centralizado em uma única pessoa, as práticas de elaboração de verbetes da Wikipédia se tornam atividades complexas e imprevisíveis. Por isso, mesmo que se chegue a um consenso ao final do processo de produçáo do verbete, fruto de muita negociação de sentidos, isso náo acontece sem gerar conflitos, divergências de opiniōes e até atos considerados não aceitáveis pela própria comunidade, como o vandalismo, que acabam, no entanto, sendo bastante produtivos para o processo colaborativo de escrita.

Assim, podemos dizer que a produção do verbete "Simone de Beauvoir" se constitui, de fato, na/por meio da mentalidade da Web 2.0, o que dialoga com o que Lankshear e Knobel (2007) caracterizam, na perspectiva dos novos letramentos, como expertise distribuída, um coletivo amplo e difuso de pessoas, interesses, inteligências e técnicas, que faz surgir e crescer o projeto da Wikipédia. É assim que os verbetes são aprimorados: com o conjunto de ediçóes se desenvolvem as mais diversas atividades por meio dos mais variados papéis, que incluem desde simples correções de digitação e de links quebrados, até as mais polêmicas disputas. Desse modo, o novo ethos de participação e colaboração ativas, associado às potencialidades técnicas que permitem uma infinidade de atividades, incentiva cada usuário a contribuir como quiser, propiciando uma série de práticas de letramentos, entre elas as de vandalismo. 


\section{Notas}

1. A questão da prova do ENEM 2015 que faz uso da frase de Simone de Beauvoir é a Questão 1 e está disponível em: <http://download.uol.com.br/vestibular2/enem2015/cadernos-de-prova/ CAD_ENEM\%202015_DIA\%201_03_BRANCO.pdf>. Acesso em: 28 nov. 2016.

2. Entendemos o verbete enciclopédico da Wikipédia como um gênero discursivo, pois se constitui por meio de "enunciados relativamente estáveis" (BAKHTIN, 2011, p. 262) que estão presentes em uma esfera de atividade específica da internet, composto de conteúdo temático, estrutura composicional e estilo. Contudo, vale destacar que este artigo não tem como foco promover uma discussão dos verbetes como gênero discursivo, mas sim como um processo de escrita colaborativa na lógica da Web 2.0, em que se analisam marcas autorais específicas dos sujeitos envolvidos, entre elas a do próprio "vandalismo".

3. Informaçôes disponíveis em: <https://pt.wikipedia.org/wiki/Wikip\%C3\%A9dia:P\%C3\%A1gina_ protegida $>$. Acesso em: 27 nov. 2016.

4. Reversão "é o nome dado à utilização de duas ferramentas semelhantes, os botôes desfazer e reverter, com os quais um editor altera uma página para uma versão precedente" do verbete, isto é, com a simples utilização do botão o usuário retorna o verbete a um estado anterior, ignorando a última edição. Disponível em: <https://pt.wikipedia.org/wiki/Ajuda:Guia_de_edi\%C3\%A7\% C3\%A3o/Reverter_edi\%C3\%A7\%C3\%B5es>. Acesso em: 27 nov. 2016.

5. $\mathrm{Na}$ versão em português, são considerados autoconfirmados usuários com contas com mais de 4 dias e que já tenham feito um mínimo de 10 ediçôes; usuários que utilizam redes de anonimato são exceçôes e, para eles, os requisitos são ampliados para 90 dias e 100 ediçôes.

6. A lista completa das vantagens dos usuários cadastrados está disponível em: <https://pt.wikipedia.org/wiki/Wikip\%C3\%A9dia:Usu\%C3\%A1rios_registrados>. Acesso em: 27 nov. 2016.

7. Dado referente ao dia 09 de outubro de 2016.

8. Disponível em: <https://pt.wikipedia.org/wiki/Wikip\%C3\%A9dia:Vandalismo>. Acesso em: 09 out. 2016.

9. Os verbetes da Wikipédia são documentos de acesso público. Estão disponíveis em: <https:// pt.wikipedia.org/w/index.php?title=Simone_de_Beauvoir\&action=history>. Acesso em: 22 nov. 2016.

10. Apesar de os dados serem públicos, por razóes éticas optamos por trocar os nomes dos usuários.

11. A esse respeito, a comunidade da Wikipédia esclarece que: "a reversão tende a ser hostil, fazendo a edição na Wikipédia ser algo pouco prazerosa. Algumas vezes isso provoca uma hostilidade recíproca de re-reversão. Às vezes isso também leva os editores a abandonarem a Wikipédia, temporariamente ou não, especialmente os mais calmos. Esse resultado é claramente prejudicial ao desenvolvimento da Wikipédia e, portanto, considerações ponderadas e justas devem ser aplicadas a todas as reversōes". Disponível em: $<$ https://pt.wikipedia.org/wiki/Wikip\%C3\%A9dia:Reverta_apenas_quando_necess\%C3\%A1rio>. Acesso em: 18 nov. 2016 . 
12. Por termos acesso também às páginas de edições, pudemos notar que Lucas realizou sozinho quase $10 \%$ das ediçôes e mais de 50\% das adiçôes de texto final do verbete "Simone de Beauvoir".

\section{Referências}

ALLEN, N. J. et al. What experienced collaborators say about collaborative writing. Journal of Business and Technical Communication, v. 1, n. 2, p. 70-90, 1987. Disponível em: shttp://journals.sagepub.com/doi/10.1177/105065198700100206>. Acesso em: 18 maio 2018. https://doi.org/10.1177/105065198700100206

BAKHTIN, M. Gêneros do discurso. In: BAKHTIN, M. Estética da Criaçáo Verbal. Tradução de Paulo Bezerra. 6. ed. São Paulo: Martins Fontes, 2011. p. 261-306.

BRUNS, A. Towards Produsage: futures for user-led content production. In: INTERNATIONAL CONFERENCE ON CULTURAL ATTITUDES TOWARDS TECHNOLOGY AND COMMUNICATION. Proceedings [...]. Perth: Murdoch University, 2006.

CASTELLS, M. A sociedade em rede. A era da informação: economia, sociedade e cultura. 6. ed. São Paulo: Paz e Terra, 2003. v. 1.

CASTELLS, M. The rise of the network society. 2. ed. Nova Jersey: Wiley-Blackwell, 2010. v. 1.

COPE, B.; KALANTZIS, M. Design in Principle and Practice: A Reconsideration of the Terms of Design Engagement. The Design Journal, v. 14, n. 1, p. 45-63, 2011. https:// doi.org/10.2752/175630610X12877385838768

COPE, B.; KALANTZIS, M. Towards a new learning: The scholar social knowledge workspace, in theory and practice. E-Learning and Digital Media, v. 10, n. 4, p. 332-356, 2013. Disponível em: <http://newlearningonline.com/ uploads/2 Cope ELEA 104 article1 web.pdf>. Acesso em: 19 jan. 2017.

DAMIANI, M. F. Entendendo o trabalho colaborativo em educação e revelando seus benefícios. Educar em Revista, n. 31, p. 213-230, 2008. http://dx.doi.org/10.1590/ $\underline{\text { S0104-40602008000100013 }}$

LANKSHEAR, C.; KNOBEL, M. Sampling "the new" in new literacies. In: LANKSHEAR, C.; KNOBEL, M.; BIGUM, C.; PETERS, M. (orgs.). A new literacies sampler. Nova York: Peter Lang, 2007. Disponível em: shttp://everydayliteracies.net/ files/NewLiteraciesSampler 2007.pdf>. Acesso em: 3 dez. 2015.

LÉVY, P. Cibercultura. São Paulo: Editora 34, 1999.

LOWRY, P. B.; CURTIS, A.; LOWRY, M. R. Building a Taxonomy and Nomenclature of Collaborative Writing to Improve Interdisciplinary Research and Practice. Journal of Business Communication, v. 41, n. 1, p. 66-99, 2004. https://doi. org/10.1177/0021943603259363

O'REILLY, T. What is Web 2.0? Design Patterns and Business Models for the Next Generation of Software. 2005. Disponível em: <http://oreilly.com/pub/a/web2/archive/ what-is-web-20.html $>$. Acesso em: 2 jun. 2016. 
PINHEIRO, P. A era do "Multissinóptico": que (novos) letramentos estão em jogo? Educaçáo em Revista, v. 30, n. 2, p. 137-160, 2014. Disponível em: <http://www.scielo. br/scielo.php?.pid $=S 0102-46982014000200007 \&$ script $=$ sci abstract $\&$ tlng $=$ pt $>. \quad$ Acesso em: 17 maio 2018. http://dx.doi.org/10.1590/S0102-46982014000200007

PINHEIRO, P. Práticas Colaborativas de Escrita Via Internet: Repensando a Produção Textual na Escola. Londrina: Eduel, 2013.

PINHEIRO, P. Práticas discursivas de participação política na internet: uma perspectiva do dissenso. Revista de Estudos da Linguagem, Belo Horizonte, v. 22, n. 2, p. 219-252, 2014. http://dx.doi.org/10.17851/2237-2083.22.2.219-252

WENGER, E. Communities of practice: learning, meaning, and identity. Cambridge: Cambridge University Press, 1998.

Recebido em 12 de dezembro de 2017.

Aceito em 12 de junho de 2018. 